\title{
A REVIEW OF LITERATURE IN MODELING APPROACHES FOR SUSTAINABLE DEVELOPMENT
}

\author{
Masoud Fakhimi \\ Department of Information Systems and Computing \\ Brunel University \\ London, UB8 3PH, UK \\ Lampros Stergioulas \\ Department of Information Systems and Computing \\ Brunel University \\ London, UB8 3PH, UK
}

\author{
Navonil Mustafee \\ University of Exeter Business School \\ Exeter EX4 4ST, UK \\ Tillal Eldabi \\ Brunel Business School \\ Brunel University \\ London, UB8 3PH, UK
}

Centre for Innovation and Service Research

\begin{abstract}
Modeling \& Simulation (M\&S) studies have been widely used in industry to gain insights into existing or proposed systems of interest. The majority of these studies focus on productivity-related measures to evaluate system' performance. However, this predominant focus on productivity may need to change since sustainability has become an increasingly important consideration in managerial discourse on organizational development. In this paper, the authors review and argue for a hybrid/mixed method approach towards modeling for sustainability; they present a review of literature with the aim of providing a synthesized view of M\&S approaches which have previously been used to model sustainability; this study also explores the specific characteristics of sustainability in order to investigate the challenges in developing models for sustainability and to analyze what seems to be a holy grail for modelers.
\end{abstract}

\section{INTRODUCTION AND MOTIVATION}

There is a growing awareness among stakeholders that their success is dependent on balanced treatments of organizations' three main responsibilities (Economic, Social and Environmental) with respect to their strategic priorities through the lens of Triple Bottom Line (TBL). TBL is a framework (see figure 1) that guides organizations to harness their three main responsibilities towards achieving a sustainable success (Vanclay 2004; Elkington 1997). TBL can help ensure organizations will remain profitable into the future though having respect for environment and society (Jamali 2006). Harmonious synergies achieved through TBL, can deliver a 'win-win' situation that permits the success in achieving multiple interconnected aims - economic, social and environmental - together.

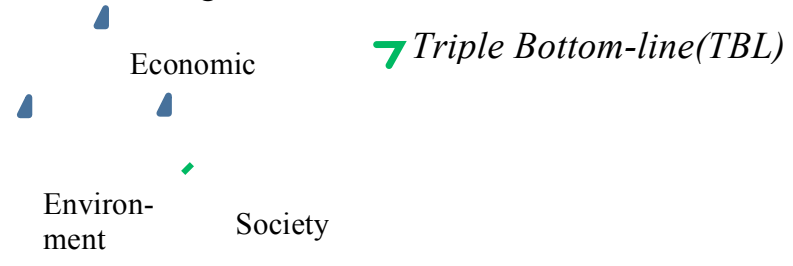

Figure 1 The spheres of sustainable development 
As sustainability is becoming more vital for organizations, dealing with its challenges are also becoming more complex and costly. Developing models to respond to these complexities requires insight into the characteristics of sustainability and sustainable system, and also a major rethinking on studying sustainability beyond traditional modeling disciplines. Computer simulation could be valuable in providing this understanding and insight in coping with systems with high levels complexity and uncertainty. For the purposes of this research, a sample review has been conducted in order to categorize and cluster academic literature pertaining to the use of computer simulation for addressing sustainability issues. It is expected that this would, in turn, help in discovering the current developments in the application of simulation techniques for sustainability purposes.

There are various simulation techniques, each with its underlying theoretical and methodological foundations, for example, System Dynamics (SD) adopts a holistic systems perspective and uses stocks, flows and feedback loops to study the behavior of complex systems over time; Agent-Based Simulation (ABS) takes a bottom-up approach to modeling wherein the overall behavior of the system emerges from the underlying dynamic interaction between the agents; Monte Carlo simulation (MCS) relies on repeated random sampling from known probability distributions to compute a result; Discrete Event Simulation (DES) is used to model queuing systems (Mustafee, Katsaliaki and Taylor 2010). It therefore follows that specific modeling techniques may be more appropriate for modeling particular classes of operations' problems. However, the complexity of systems being modeled and their multi-faceted relationships may mean that combining simulation methods will reduce the limitations and increase the capabilities of the individual methods, thereby potentially realizing synergies across techniques and facilitating greater insights to problem solving (Fakhimi and Mustafee 2012). In this paper, the authors propose the use of such hybrid M\&S for modeling systems in which both productivity and other sustainability criterion are important considerations.

Hybrid M\&S have been applied in various domains, such as, construction, e.g., combined DES and continuous simulation (AbouRizk and Wales 1997); container loading, e.g., combined application of ABS and load plan construction heuristics (Mustafee and Bischoff 2013); healthcare, e.g., combined application of SD and DES (Chahal and Eldabi 2008); supply chains, e.g., combined application of analytic hierarchy process technique, SD and DES (Rabelo et al. 2007). We now use the example of two simulation techniques to put forward our case for hybrid simulation for modeling sustainability. As mentioned earlier, DES is used to model queuing systems and is therefore an ideal technique to gain further understanding of the system in terms of productivity measures, e.g., average service time, identification of bottlenecks, utilization of resources and average queue time. On the other hand, a simulation technique like SD may be more appropriate for strategic modeling of the interplay between the TBL of sustainability. Thus, a hybrid simulation that combines DES and SD may be more effective in modeling sustainability when compared to using these techniques in isolation. However, this is only one example and there may be several single-technique and hybrid approaches to modeling sustainably that is reported in literature; and it is with this aim that we present a review of literature in modeling approaches for sustainability.

The remainder of the paper is organized as follows. The challenge of modeling sustainability is briefly described in section two. Section three outlines the methodology for the literature review. This is followed by sections four and five, which present the results and discuss the findings. Section six is the concluding section. It summarizes the research and draws the paper to a close.

\section{THE CHALLENGE OF MODELING FOR SUSTAINABILITY}

To ensure that the results of simulation are applicable to the real world, modelers must understand the definitions, assumptions, conceptualizations, and implementation constraints of this emerging field. However, the challenge initiates from knowing that there is no single interpretation for the phenomenon of sustainability. United Nation defines sustainable development as: "Development that meets the needs of the present without compromising the ability of future generations to meet their own needs" (WCED 1987). This definition is considered as a reference for sustainability studies and it shows the direction ra- 
ther than providing a single and unique definition for sustainability. It is therefore not surprising that in spite of the frequency with which the term "sustainability" is invoked, the concept remains unexpectedly vague and this ambiguity results in large number of definitions and explanations.

It can be argued that there are two main reasons why modelers may find it difficult to follow these definitions; first, the debates on the definition of scope of sustainability disregard the range of time and space over which this concept has to apply (Cleveland et al. 1996); second, they ignore the high level of uncertainty and flexibility associated with sustainability. However, and despite the fact that critics argue that the concept of sustainability cannot be modeled as it is not "adequately defined", our literature review attempts to build a reference set of scholarly contributions on the subject of modeling for sustainability.

\section{METHODOLOGY FOR LITERATURE REVIEW}

Our literature review methodology has been influenced by the systematic literature review approach adopted by Eddama and Coast (2008), wherein scholarly databases were searched using a combination of search terms and the final set of papers were selected by applying specific inclusion criterion. We used the ISI Web of Science ${ }^{\circledR}$ database to conduct our search; it is one of the largest databases of quality academic journals and conferences and provides access to bibliographic information pertaining to around 8500 impact factor research journals. To identify articles that would be incorporated in our dataset, the following criterion was used: inclusion of the words, 'sustainabl*' AND 'simulation*' in the article's topics. The use of the asterisk allowed for the inclusion of keyword derivatives in the search options. The restricted the search to only articles and review papers written in the English language from 1970 until 2012 (both inclusive). We further filtered the search results to include only papers indexed under the ISI subject category 'OPERATIONS RESEARCH MANAGEMENT SCIENCE'. This resulted in a total of 164 papers. The abstract of the papers were then critically reviewed in order to ascertain the suitability of including them in our final dataset; when the abstract did not provide sufficient information to make inclusionexclusion decision the full text was referred to. The appraisal was carried out based on the following inclusion criteria - the selected papers should evidently demonstrate strong relation with the TBL or should have directly considered at least either of the environmental or social responsibilities in the modeling study.

However, the boundaries between the papers that considered the TBL and those that focused either on the environment, the economy or the society, or a combination thereof, were not always straightforward. In many papers the impact on social responsibility was implied rather that explicitly stated. In such cases the reviewers took a flexible approach of including papers that clearly related the problem described with some kind of sustainability impact. Applying the inclusion-exclusion criterion, we were left with 69 papers and this was the underlying dataset for the literature review.

\section{RESULTS}

Our literature review focused on investigating the following. First, the identification of simulation techniques (including hybrid techniques) that have been used for modeling sustainability and to find the frequency of their application (section 4.1). Second, to classify the studies based on the aspect of sustainability being modeled, for e.g., studies could have focused on the TBL, or either the environment, the economy or the society, or a combination thereof (section 4.2). Third, to identify the application domains in which these studies have been applied (section 4.3).

\subsection{Simulation Techniques}

Out review of literature shows that SD is by far the method of choice in modeling sustainability. Approx. $28 \%$ of studies have applied SD and they have applied it as a single technique (i.e., not in combination with another techniques). This is followed by numerical modeling which account for approx. $17 \%$ of studies. Hybrid simulation has been used in approx. 14\% studies, followed by DES $12 \%$. The review also 
identified a number of studies $4 \%$ that did not report on model development but concerned primarily with review of literature, theoretical framework, etc. The use of ABS, MCS, DSS and Mathematical programming were repaired in studies $7 \%, 4 \%, 6 \%$ and $7 \%$ respectively.

\subsection{Aspects of TBL Being Modeled}

In this section, we classify the studies not only based on the M\&S technique used, but also according to the aspect of sustainability being modeled. Thus in Figure 2 the stacked chart shows the number of studies that have considered, (a) the TBL, or in other word, the three pillars of sustainability, (b) studies that have looked only on the environment and economic aspects, (c) studies which focused on the environmental and the social factors, (d) studies that explored the social and economic aspects, and (e) studies that related only to the environment. There were no studies that focused only on the social responsibility. In figure 2 the $\mathrm{x}$-axis lists the simulation techniques and the frequency of its application is reported in the y-axis.

We now present aggregate statistics pertaining to aspects of sustainability that have been modeled. According to our findings only $10 \%$ of articles have considered the TBL. On the other hand, $75 \%$ of the studies have focused on the economic and the environmental aspects of sustainability. With regard to SD, only $15 \%$ of articles have addressed the TBL (e.g. Duran-Encalada and Paucar-Caceres 2012) whereas approx. 68\% have focused on the Economic-Environmental issues (e.g. Tu, Leng and Jia 2009). In the context of hybrid M\&S, only one article has addressed TBL (Paju 2010), approx. 70\% studies have applied this combined approach to model Economic-Environmental factors (e.g., Morales-Mendoza 2012) and around $20 \%$ of studies are only concerned with the environmental issues (e.g., Nguyen and Walker 2005).

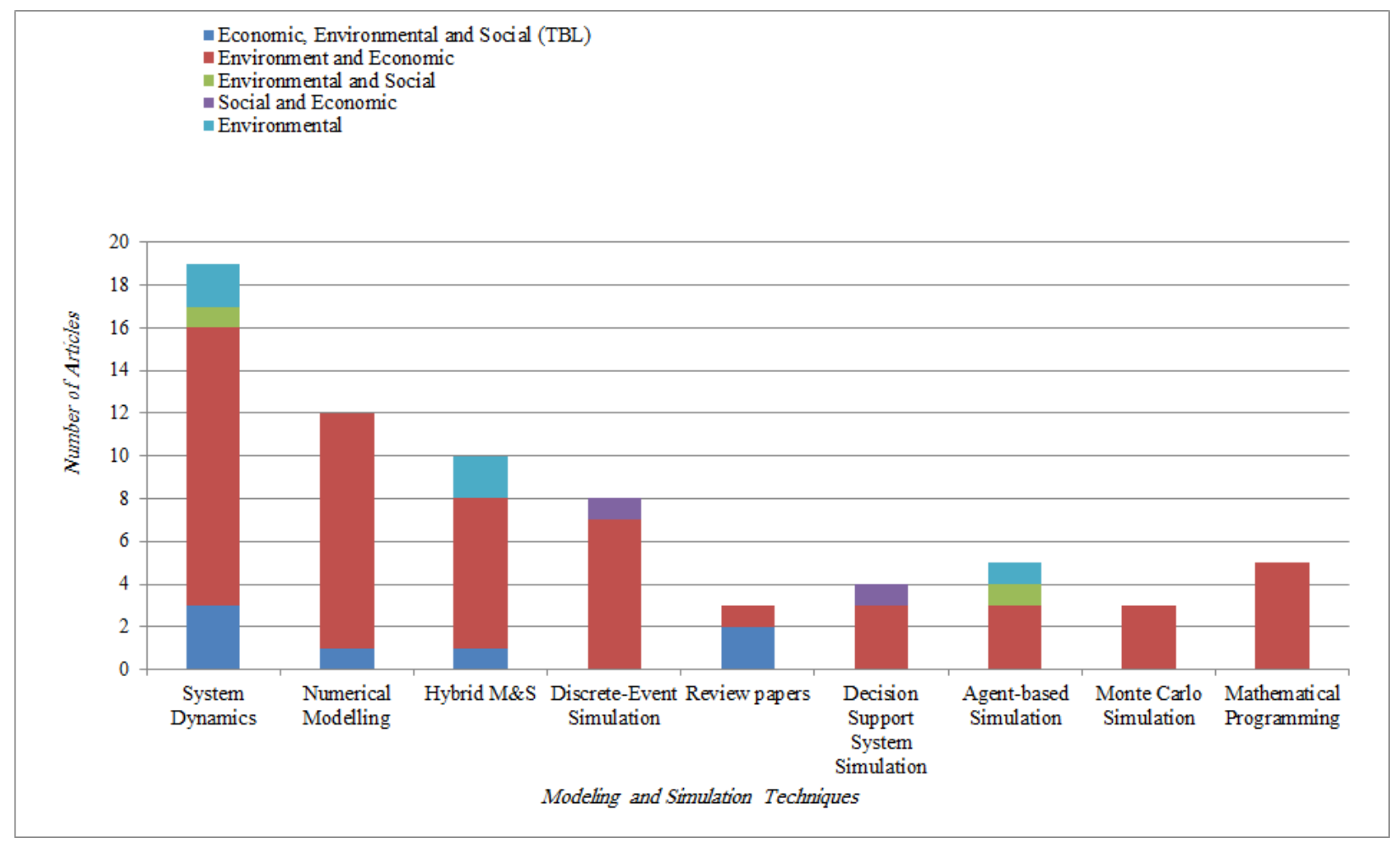

Figure 2: Simulation techniques and the frequency of their application to address sustainability issues 


\subsection{Application Areas}

According to our findings around $42 \%$ of studies have developed a model for manufacturing sector, $35 \%$ are related to ecosystem models, $14 \%$ of models are related to regional and urban modeling, $5 \%$ of papers have developed a model for agriculture sector, and 3\% also used modeling techniques to address sustainability in the transportation sector (Figure 3). One comment here is that none of the articles have applied modeling for sustainability in the context of healthcare.

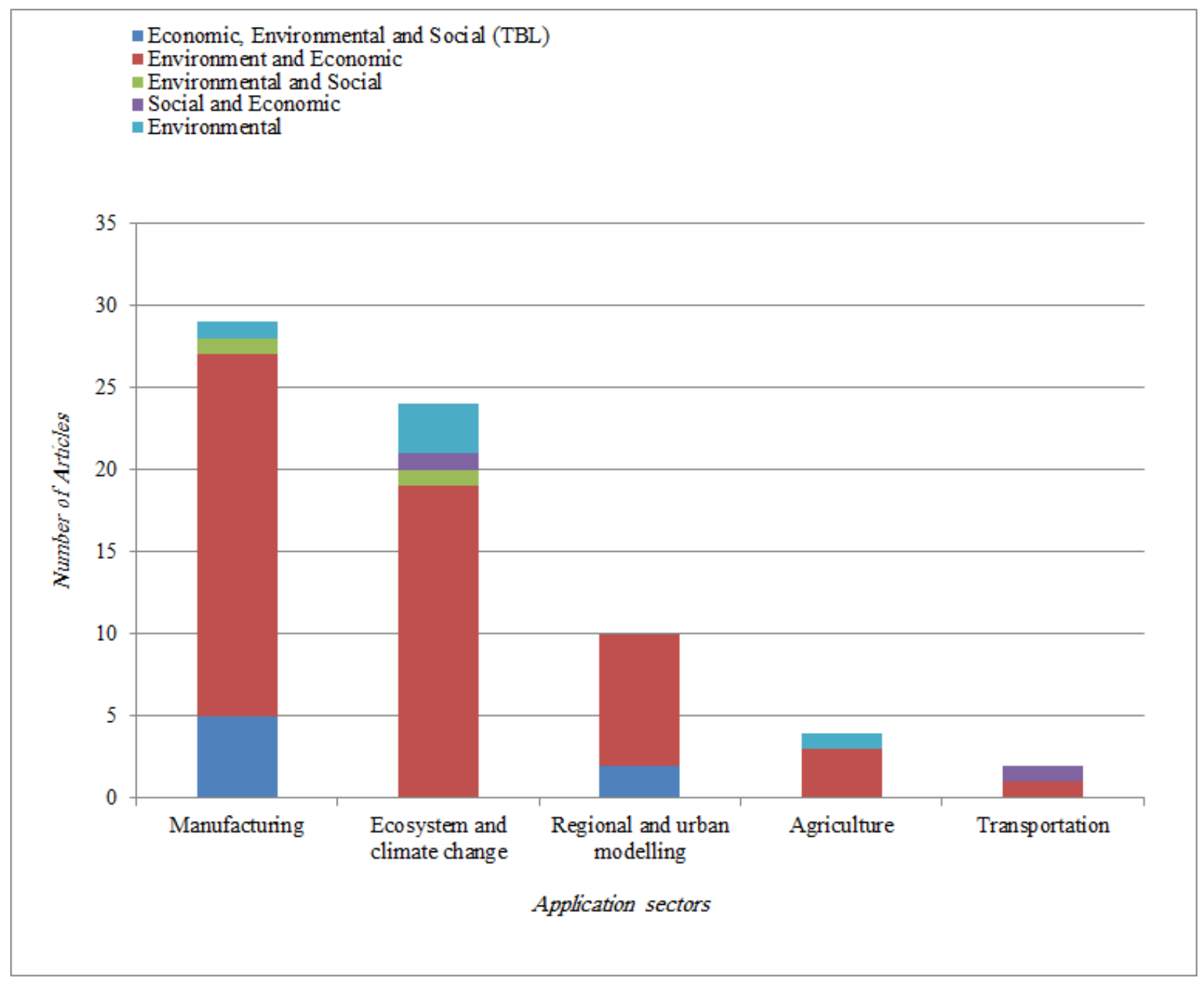

Figure 3: Application of simulation techniques to address sustainability in different sectors

\section{DISCUSSION}

The review of existing M\&S studies have shown an imbalance in the treatment of economic, social and environmental aspects of sustainability. This is perhaps aptly demonstrated by the fact that only $11 \%$ of studies have addressed TBL in their models. Furthermore, it can be argued that the limited numbers of studies that have tried to address TBL in their models have not fully aligned it with their long-term organizational strategies. The scarcity of literature and empirical models in this field shows that challenges still remain in implementation and validation of the models, or in biblical language: "the mind is willing, but the flesh is weak". Modelers "willing mind" requires further refinement but they need to pray for stronger flesh (Meadows, Meadows, and Randers 2004). The following section explores the five main characteris- 
tics of sustainability in order to analyze why modeling TBL may perhaps require a shift in traditional modeling paradigms.

\subsection{Vagueness and Ambiguity}

Sustainability issues are vague, indefinite, disputable, and has several variables that are hard to quantify (IISD and WBCSD 2002; Paramanathan 2004; Hilty, Seifert and Treibert 2005; Azapagic 2003). Consequently, the fuzziness and irregularity in sustainability concepts have led to inconsistency and contradiction in choosing the sustainability variables; it has also led to the modelers misunderstanding the impacts of sustainability issues on a given system. Although uncertainty and vagueness related to sustainability will always remain but it is expected that this vagueness will gradually decrease by translating sustainability concepts to quantitative models and numerical regime.

\subsection{Difficulty of Balancing the Triple Bottom Line}

The basic withdrawal factor from traditional modeling approaches to departure towards sustainability lies in the fact that although organizations' survival is mainly dependent on profit, the economic and financial benefits are not adequate for continuing success of organizations (Gladwin, Kennelly, Krause 1995). As discussed previously, the crux of sustainability is on inseparable and integrated three-legged stool - the so called TBL - and achieving success in each of them is not achievable by disregarding the other two (Keating 1993). Therefore, modeling for sustainability concepts would involve a complex web of decisionmaking institutions and indicators. As 1) there is no comprehensive and generally accepted set of sustainability indicators and sometimes they are very broad and exhaustive, 2) Complexity, to develop a model for sustainability purposes, is becoming more as TBL factors sometimes are holding opposite values. As a result, for modelers, using only classical modeling disciplines, cannot find a practical solution to integrate and align all TBL elements toward single purpose.

\subsection{Data Complexity}

If sustainability is to be modeled using single traditional simulation technique, it requires such set of data holding set of features like, concerning the system holistically, has quantitative character for measurable and immeasurable elements of the system, containing parameters which can be used for longer period of time, giving clear indication that it is concerned all triple bottom line framework. Arguably, a set of data with mentioned characters is not easily collectable.

\subsection{Uncertainty}

Due to the high level of uncertainty, sustainability, essentially, is a highly dynamic and hardly predictable concept. According to its characteristics, sustainability naturally is flexible, which replicates the variety of its interpretations. This high level of uncertainty leads to the fact that optimum point of sustainability is not fixed (Hjorth and Bagheri 2006) and it is, arguably, not predictable. Therefore, developing a simulation modeling for an uncertain and flexible phenomenon like sustainability may requires incremental change in modeling paradigms.

\subsection{Morality and Social Norms}

In essence, sustainability model systematically deals with set of normative factors with the "Value level" goals that indicators and variables of the model have to originate from practical and pragmatic levels. Therefore, developing such model with existing modeling paradigms seems hardly achievable.

According to the above discussion, this study basically argues that sustainability is not a result to achieve rather it is an un-ending process which cops with high level of uncertainty and complexity. Therefore, traditional modeling disciplines are not capable enough to develop a model for TBL. To tackle this challenge following section explores the application of Hybrid M\&S in order to develop, monitor, and validate the model for sustainability. 
Sustainability is basically a strategic concept rather than day to day planning and control actions (Bettley and Burnley 2008) therefore SD could make unique contributions to strategic modeling with continuous variables (Kibira, Jain, and McLean 2008; Brailsford, Churilov, and Liew 2003; Jain and Kibira 2010). Our literature review also indicates that SD is the most applied modeling technique to address sustainability issues. On the other hand, despite the increasing trend of application of SD to develop a model for sustainability, some challenges in implementation and validation of the SD models still remained unsolved. This research argues that this gap may attribute to important intrinsic characteristics of sustainability and SD models which seems are neglected by some modelers. As mentioned earlier, sustainability entails a set of vague, unending and non-deterministic processes with the end point not known in advance. Therefore measuring sustainability is not easily feasible (Bell and Morse 2003). As a result, sustainability has to be seen as a process to monitor rather than result to achieve. Therefore, implementing sustainability without running a monitoring model is not achievable. Consequently, a SD model has to be considered as a strategic model to monitor the system to ensure the changes will not make the given system unsustainable (Bagheri and Hjorth 2005). Additionally, due to fuzziness and un-ending features of sustainability, it is hardly feasible to validate such SD model using traditional Structural-Behavioral validity methodologies. Hence, to tackle challenges in implementation and validation and to minimize the limitation of SD models, this study proposes application of hybrid M\&S for developing model for sustainability. According to the literature a synchronized SD-DES hybrid approach will provide a more realistic picture of complex systems (Chahal and Eldabi 2008; Brailsford and Hilton 2001). Therefore, arguably, hybrid simulation based method involving of SD components at the strategic level and DES components at the lower operational level is expected to be the fine-fitted to ensure system will remain sustainable for a long term.

\section{CONCLUSION}

Sustainability has been among the fastest-growing areas of activity in research in recent decades. Despite this, the simulation and modeling methodologies for implementing and managing Triple Bottom Line of sustainability are in their infancy. As sustainability is a multi-disciplinary science, researchers can apply simulation to a multitude of issues relating to sustainability and publish their works in a number of unrelated publishing outlets, and this fact may hamper the widespread reference and use of such resources. Hence, this paper presents a sample literature review in order to provide a synthesized view of M\&S approaches which have been used in the past to model sustainability issues in different industries with the aim of ascertain of applying hybrid modeling to address sustainability issues. The results of the review show the field of $M \& S$ has yet to recognize the complex interdependencies of the Triple Bottom-Line. According to the findings of this paper, sustainability is a concept with very specific characteristics which, arguably, are not compatible with traditional modeling disciplines. Therefore, developing a model for TBL requires a shift in modeling paradigms in order to ensure the system is aligned with organizational strategy and remains sustainable for a long time.

\section{REFERENCES}

AbouRizk, S. M., and R. J. Wales. 1997. "Combined Discrete-Event/Continuous Simulation for Project Planning." Journal of Construction Engineering and Management. 123(1):11-23.

Azapagic, A. 2003. "Systems Approach to Corporate Sustainability: A General Management Framework." IChemE Trans. Vol. 81, Part B, PP. 303-316.

Bagheri, A., and P. Hjorth. 2005. "Monitoring for Sustainable Development: A Systemic Framework." International Journal of Sustainable Development. Inderscience Enterprises Ltd, vol. 8(4), PP. 280-301.

Bell, S., and Morse, S. 2003. "Measuring Sustainability: Learning by doing. Sterling." VA: Earthscan Publications Ltd. 
Bettley, A., and S. Burnley. 2008. "Towards Sustainable Operations Management Integrating Sustainability Management into Operations Management Strategies and Practices". In Handbook of Performability Engineering. Springer London. pp. 875-904.

Brailsford, S.C. and N.A. Hilton. 2001. "A Comparison of Discrete Event Simulation and System Dynamics for Modelling Health Care Systems. Planning for the Future: Health Service Quality and Emergency Accessibility. Operational Research Applied to Health Services (ORAHS), Glasgow Caledonian University, pp. 18-39.

Brailsford, S.C., L. Churilov, and S.K. Liew. 2003. "Treating Ailing Emergency Departments with Simulation: An Integrated Perspective". In Proceedings of Western Multiconference on Health Sciences Simulation, Society for Modelling \& Simulation International (SCS), Orlando, FL and San Diego, CA, pp. 25-30.

Chahal, K., and T. Eldabi. 2008. "Applicability of Hybrid Simulation to Different Modes of Governance in UK Healthcare." In Proceeding of the 2008 Winter Simulation Conference. Piscataway, New Jersey: Institute of Electrical and Electronics Engineers, Inc. PP.1469 - 1476

Cleveland, C., R. Costanza, T. Eggertsson, L. Fortmann, B. Low, M. McKean, E. Ostrom, J. Wilson, and O. Young. 1996. "A Framework for Modeling the Linkages between Ecosystems and Human Systems". Beijer Discussion Paper Series No. 76. Sweden: Beijer Institute of Ecological Economics, Royal Swedish Academy of Sciences.

D.H. Meadows, D.L. Meadows, and J. Randers. 2004. "Limits to Growth-The 30-Year Update", first ed., Chelsea Green, White River Junction, VT.

Duran-Encalada, J.A. and A. Paucar-Caceres. 2012. "A System Dynamics Sustainable Business Model for Petroleos Mexicanos (Pemex): Case Based on the Global Reporting Initiative". Journal of the Operational Research Society. 63(8), PP. 1065-1078.

Eddama, O. and J. Coast. 2008. "A Systematic Review of the Use of Economic Evaluation in Local Decision-Making”. Health Policy. 86:129-141.

Elkington, J. 1997. "Cannibals with Forks: The Triple Bottom Line of 21st Century Business." Oxford: Capstone Publishing.

Fakhimi, M., and N. Mustafee. 2012. "Applications of Operations Research within the UK Healthcare Context". In Proceedings of the 2012 OR Society Simulation Workshop (SW12). UK OR Society. PP. 66-82

Gladwin T, J. Kennelly, T.S. Krause, 1995. "Shifting Paradigms for Sustainable Development: Implications for Management Theory and Research." Academy of Management Review. 20(4): 874-907.

Hilty, L., E. Seifert, and R. Treibert. 2005. "Information Systems for Sustainable Development" Idea Group Publishing.

Hjorth, P., and A. Bagheri. 2006. "Navigating Towards Sustainable Development: A System Dynamics Approach.” Futures, Volume 38, Issue 1. PP. 74-92.

International institute for sustainable development and World Business Council for Sustainable Development (IISD \& WBCSD). 2002. Mining, Minerals and Sustainable Development Project. http://www.iied.org/mmsd [Accessed May 19, 2013].

Jain, S., and D. Kibira, 2010. "A Framework for Multi-Resolution Modeling of Sustainable Manufacturing." In Proceedings of Winter Simulation Conference 2010, Baltimore, MD. pp. 3423-3434.

Jamali, D. 2006. "Insights into triple bottom line integration from a learning organization perspective." Business Process Management Journal, 12(6):809-821.

Keating, M. 1993. "The Earth Summit's Agenda for Change." Centre for Our Common Future: Geneva.

Kibira, D., S. Jain, and C.R. McLean. 2008. "A Systems Dynamics Framework for Sustainable Manufacturing." In Proceedings of Systems Dynamics Society Conference, Albuquerque, NM, July 26-30.

Morales-Mendoza, L. F., C. Azzaro-Pantel, J. P. Belaud, L. Pibouleau, and S. Domenecha. 2012. "An Integrated Approach Combining Process Simulation and Life Cycle Assessment for Eco-efficient Pro- 
cess Design." In proceedings of 22nd European Symposium on Computer Aided Process Engineering. Vol. 17, PP. 142-146.

Mustafee, N. and E.E. Bischoff. 2013. "Analysing Trade-offs in Container Loading: Combining Load Plan Construction Heuristics with Agent-based Simulation." International Transactions in Operational Research. Available as early view.

Mustafee, N., K. Katsaliaki, and S.J.E. Taylor. 2010. "Profiling Literature in Healthcare Simulation." SIMULATION: Transactions of the Society of Modelling and Simulation International, 86(8-9): 543558.

Nguyen, H. 2005. “The Effect of Irrigation Schedules on Water Table Depth and Root Zone Soil Moisture." MODSIM 2005: International Congress on Modelling and Simulation: Advances and Applications for Management and decision Making. PP. 1286-1292.

Paju, M. J. Heilala, M. Hentula, A. Heikkila, B. Johansson, L. Swee, and K. Lyons. 2010 "Framework and Indicators for a Sustainable Manufacturing Mapping Methodology." In Proceedings of the 2010 Winter Simulation Conference, pp. 3411, 3422.

Paramanathan, S., C. Farrukh, R. Phaal, and D. Probert. 2004. "Implementing Industrial Sustainability: The Research Issues in Technology Management." R\&D Management. 34(5). PP. 527-537.

Rabelo, L., H. Eskandari, T. Shaalan, and M. Helal. 2007. "Value Chain Analysis using Hybrid Simulation and AHP." International Journal of Production Economics. 105(2):536-547.

Tu, G., B. Leng, and R. JIA. 2009. "Evaluation and SD Simulation on Energy Use Efficiency of 3E System of China". In Proceedings of 2009 Conference on Systems Science, Management Science and System Dynamics, Vol 6, PP. 149-155.

Vanclay, F. 2004. "Impact Assessment and the Triple Bottom Line: Competing Pathways to Sustainability?" In Proceedings of Sustainability and Social Science Round Table (conference held Dec 2003), Sydney. pp. 27-39.

World Commission on Environment and Development (WCED). 1987. "Our Common Future." Oxford University Press, New York.

\section{AUTHOR BIOGRAPHIES}

MASOUD FAKHIMI is a PhD student and research assistant in the School of Information Systems, Computing and Mathematics at Brunel University London. His research interests include Operations research, simulation and modeling, sustainable development, and green supply chain management. His email address is masoud.fakhimi@brunel.ac.uk.

NAVONIL MUSTAFEE is a lecturer in Operations and Supply Chain Management at University of Exeter Business School. His research interests are in simulation methodologies, parallel and distributed simulation and healthcare simulation. His e-mail address is n.mustafee@exeter.ac.uk and his webpage is http://sites.google.com/site/navonilmustafee/.

LAMPROS STERGIOULAS is a reader in the School of Information Systems, Computing and Mathematics at Brunel University London. His research interests include information engineering, medical and health informatics, human centered information management, and biomedical data analysis. His e-mail address is lampros.stergioulas@brunel.ac.uk.

TILLAL ELDABI is a senior lecturer in Brunel Business School. His research is in aspects of Healthcare management and the intervention of simulation and his main research also concentrates on the economy of Healthcare delivery. His e-mail address is tillal.eldabi@brunel.ac.uk. 